\title{
Cosmopolitan Communities
}

\author{
Bernardo Figueiredo, University of New South Wales, bernardo@unsw.edu.au \\ Julien Cayla, University of New South Wales, julienc@agsm.edu.au
}

\begin{abstract}
This research contributes to the poststructuralist stream on consumer cosmopolitanism by exploring the role of a cosmopolitan community in shaping cosmopolitan identity. It suggests that cosmopolitan communities can shape consumers' cosmopolitan identity in many ways: a) by promoting a different polarity (cosmopolitan-parochial instead of cosmopolitan-local), it shifts how consumption practices are used to maintain symbolic boundaries, b) by validating cosmopolitan ideals and preferences, it works as a catalyst in the process of becoming a cosmopolitan consumer, c) by functioning as a community of practice, it provides cosmopolitan knowledge and skills which directly influence consumer choice and usage of products, services, places and brands. Implications for marketers are discussed.
\end{abstract}

Keywords: Cosmopolitan, community, consumer cosmopolitanism, identity, practice. 


\section{Cosmopolitan Communities}

\section{Two streams of literature on consumer cosmopolitanism}

There are two streams of marketing literature on consumer cosmopolitanism. One stream characterizes cosmopolitanism as a consumer orientation (a set of acquired individual characteristics). As such, cosmopolitan consumers have particular traits such as openmindedness, a taste for the exotic, a tolerance and interest in other cultures, a tendency to look beyond one's immediate surroundings (Cannon, Yoon SJ, McGowan L, and Yaprak, 1994; Yoon, 1998). In addition, the literature posits that these traits are acquired through ways such as travels, expatriate stays, cross cultural training (Riefler and Diamantopoulos, 2009) Because the literature tends to conceptualize cosmopolitans in different ways, there is no agreement about which elements would be essential to the characterization of cosmopolitan consumers, which leads to some confusion. The scale CYMYC was created in attempt to measure levels of cosmopolitanism(Cannon, et al., 1994), but many scholars, including the ones that created the scale, have found problems with it, especially because it assumes a polar opposition between locals and cosmopolitans which does not seem to hold true for many researchers (Cannon and Yaprak, 2002). As a result, there are negative correlations among items in the scale which creates misunderstanding and imprecision (Riefler and Diamantopoulos, 2009).

Despite the problems in measurement and the current lack of clear answer to what a cosmopolitan consumer means, there is an ongoing interest of marketers in finding more about cosmopolitan consumers because of the practical advantages that it brings. First, the existence of a cosmopolitan consumer with particular lifestyle, tastes and behaviors can lead to more meaningful ways to segment consumers that are part of that lifestyle. Researchers have discussed some of consequences of consumer cosmopolitanism by trying to link the set of characteristics to other consumer behavior variables such as consumer ethnocentrism and materialism (Cleveland, Laroche, and Papadopoulos, 2009; Riefler and Diamantopoulos, 2009) . According to them, cosmopolitan consumers would e more inclined to try products and services from different countries, show interest in products from foreign countries, seek foreign newspapers, appreciate diverse cultural commodities and eat ethnic food. More importantly, because cosmopolitanism seems to be a pervasive transnational category, its existence would help marketers to sell, promote and advertise their products globally which would save costs by creating economies of scales and global synergies in marketing strategies. Despite the extant studies and their efforts to link specific behaviors with cosmopolitan consumer, which would allow cosmopolitan orientation to predict certain consumer behaviors, remains empirically unclear.

A second stream of studies tries to understand cosmopolitanism from a dynamic perspective (Holt, 1997; Skeggs and Binnie, 2004; Thompson and Tambyah, 1999). According to this poststructuralist stream, cosmopolitanism is an outcome of different cultural and social tensions lived by consumers. In these studies, rather than being a fixed set of characteristics of consumers, cosmopolitanism is a result of the interplay of specific narratives, ideologies, and cultural discourses. Being cosmopolitan varies according to which cultural and social determinants are in operation historically and contextually. This stream of research is important because it sees cosmopolitan identities as sites of struggle. The cosmopolitan identity project is an unfinished one, that is, to use Thompson and Tambyah's (1999) words, 
cosmopolitan consumers are the ones who spouse cosmopolitan ideals and who are "trying to be cosmopolitan".

This stream of studies challenges the search for direct univocal relationships between cosmopolitanism and specific behaviors since the dynamic aspect of cosmopolitanism could lead to different behaviors depending on the sociohistorical patterns (e.g. class struggles) and contextual meanings (e.g. meaning of Chinese food in a specific situation and place) in which these behaviors occur. Rather, behaviors are consequences of underlying sociocultural tensions and it might be more useful to marketers to try to understand the links between the sources of these tensions and consumer behavior. For example, Thompson and Tambyah (1999) show the cosmopolitan identity project contain countervailing dwelling and travelling narratives. Dwelling narratives are related to the quest for home and community, while travelling narratives are related to flexibility, adaptability and cultural diversity. Both narratives are present in the construction of the cosmopolitan identity. While it may be possible to associate travelling narratives to certain consumer behaviors such as a search for exotic products and dwelling narratives to other consumer behaviors such as a taste for nostalgic ethic objects representing homeland, it is important to understand the cosmopolitan identity as the interplay of these tensions, and therefore, the extent to which different types of behavior can be associated with cosmopolitanism may depend on the narrative that is more salient to consumers at a specific moment and place. Thus, to say that cosmopolitans will buy exotic products and non-cosmopolitans will not is an oversimplification of how cosmopolitan identities may be connected to consumption. The poststructuralist view requires understanding the role of contextual sociocultural forces in framing and structuring cosmopolitanism.

The poststructuralist view on cosmopolitan identities adds important dimensions to the research on cosmopolitanism in consumer behavior. According to it, to be able to fully grasp the impact of cosmopolitanism on consumer behavior, one must try to understand the underlying forces which shape the emergence, existence and realization of a cosmopolitan identity. Therefore, it becomes more relevant to marketers to understand the conditions and contextual variables that might enable cosmopolitanism to exist, the sociocultural forces which determine the symbolic boundaries of opposition, the different discourses that lie within the cosmopolitan identity project, the tensions that arise from the interplay of these discourses, and the impact of each underlying narrative in consumption practices and tastes than to try to establish fixed relationships between cosmopolitan orientation and consumer behavior, as these are likely to vary depending on the symbolic forces which are in action in the formation of cosmopolitan identities. The poststructuralist view implies that prediction of future behavior is better attained through the understanding of the sociocultural elements and dynamics around cosmopolitanism.

This study aims to contribute to this second stream of research and its quest for understanding the sociocultural forces which determine and enable cosmopolitanism by focusing on the role of cosmopolitan groups in the formation of cosmopolitan identities. So far, cosmopolitanism has been looked at mostly as an individual orientation or an individual identity project. Some poststructuralist studies acknowledge that cosmopolitanism is a shared identity project of collectivities. Holt $(1997 ; 1998)$ argues that cosmopolitanism is socially constructed and that its meaning is derived from relational differences between collectivities, but he does not explore the role of the groups and communities in the construction of cosmopolitan identities. The social dimensions present in his research are measured solely through the filter of the individual. Likewise, Thompson and Tambyah (1999) found signs of shared identity projects and recognized the importance of groups for expatriates when they observed that "the main 
vehicles for building these social networks are the expatriate clubs, organizations, and enclaves" (p.231) and when they realized that "though the intensive involvement in this support group does little to foster strong local ties, it allows [the consumer] to make rewarding use of experience of living as an expatriate". However, they also examine the social dimensions (i.e. quest for community) through the perspective of the individual narratives. Caldwell and colleagues (2006) also find that "expatriate communities play an important role in cosmopolitan identity formation" ( $p$ 136). Although these studies observe the importance of groups to the formation of cosmopolitan identities, they do not investigate how cosmopolitan communities might work in shaping cosmopolitan identities. This is surprising, considering that the marketing literature on identity has repeatedly emphasized the role of groups (Bearden and Etzel, 1982; Moschis, 1976)and communities (Cova, 1997; Kozinets, 2002; Schouten and McAlexander, 1995) in formation of social identity.

The problem with examining cosmopolitan identity solely by individual discourses is that an important shaper of these identities - the group - is left out of the research inquiry and only indirectly inferred. In addition, cosmopolitan identities, like other social identities, are best understood when they are motivated by contexts that highlight the social need for that identity (Goffman, 1959). As observed by Holt (1997:346) to plumb successfully the social patterning of consumption requires a shift in the unit of analysis from individual to collective consumption patterns. Thus, this research extends current research on cosmopolitanism in marketing by exploring the role of communities in shaping cosmopolitan identity. The main research question of this paper is: What is the role of cosmopolitan communities in shaping cosmopolitan identities?

\section{Context}

In order to extend current knowledge on the role of communities in building cosmopolitan identities, the research investigates a cosmopolitan community called Intercultures. The reason for choosing Intercultures as a context is linked to its unique characteristics. First, it is promoted as a community of global-minded people. Cosmopolitanism and international experiences are precisely the reasons around which the community is formed. This is how it is advertised and how it attracts new members. Second, its purpose is to "connect global minds"; this puts an emphasis on the collective value of the social link. Third, it has a global presence, with sub-communities located in more than 230 cities spanning all continents. In less than 3 years of existence, it has gathered more than 180.000 active members. The numbers of members and the global reach may indicate that the community has met some linking needs that were latent but not fulfilled. Fourth, it exists virtually as an online platform (as a social media package) and also in a physical form, through events that are held monthly at every location and last three to four hours. This dual existence allows members to move around and keep connected to the community. It provides a lasting sense of global connection and at the same time creates local anchors to these global identities. It is not expected that this community will provide a comprehensive understanding of all cosmopolitan communities, but it has the capacity to highlight some important links and constructs that were overlooked by previous studies on cosmopolitanism from a solely individual point of view.

\section{Method}

The method used was a multi-sited ethnography (Marcus, 1995). This method was the most appropriate to provide answers to the research questions because it engages with and works through subjective points of view with an interest in how these subjects imagine and act collectively within their multi-sited distributed worlds. The multi-sited ethnography involved 
multiple means of data collection: a) participant observation and informal interviews were conducted during the monthly community gatherings in Sydney or Toronto with a focus on understanding the role of the community in the formation of cosmopolitan identities b) semistructured interviews with members and local organizers were conducted in the period between meetings and c) netnographic methods (Kozinets, 2010) were used to investigate the online side of the community, which constitutes of webpages and webpostings in the password-protected social network. The multiple sources of data made the triangulation of findings possible, provided a means of verification and added texture to the findings. The data was analyzing through the Extended Case Method (Burawoy, 1998).

\section{Preliminary Findings and Discussion}

The community frames cosmopolitan identity different from expatriate identity. The cosmopolitan identity is formed by people who have lived in and experienced many countries/cultures (global minded-people) and, in opposition to people who don't have that experience and capability. All members of the community (locals and non-locals) have in common the fact that they consider themselves global-minded people. Expatriates (i.e. members from other countries) have chance to reframe themselves as cosmopolitans because they shift their social relationships of opposition to locals (i.e. the opposite of an expatriate), to opposition to local-minded. Likewise, current local consumers, who have lived abroad in the past, or just feel more cosmopolitan than other locals, have a chance to access the cosmopolitan identity by engaging with global-minded people, sharing stories, feelings, ideas, practices and perspectives on the world. Cosmopolitanism in this community therefore is framed as an ideological stance that has much less to do with being or not being from a locality and much more to do with the self-identification with global minded perspective.

This shift of polarities in social identities from cosmopolitan-local to cosmopolitanparochial is theoretically supported by Cannon and Yaprak (2002), and it has important consequences for consumer research. According to the poststructuralist stream, individuals and groups may engage in certain consumption practices to differentiate themselves from groups they want to distant themselves from (out-groups). Since cosmopolitanism is constructed in opposition to parochialism, and not to localism, this suggests that members of these cosmopolitan communities can engage in the consumption of local products, services and brands, as long as they are consumed in a non-parochial way. For example, in the studied community member would meet every time in a different bar or restaurant in town, usually upscale places in the centre of town or trendy artsy districts. Their goals it to explore different places and it is fine to go to places that are very representative of local culture as long as it is intertwined with visits to other types of restaurants and bars. It is by alternating consumption of places that cosmopolitans differentiate themselves from parochial, and the local is used as part of the ingredients in showing this flexibility to seek the new and adapt.

The community functions as a catalyst for social processes of differentiation. Members of the community report negative emotions and feelings of being misunderstood from noncosmopolitans. Cosmopolitan consumers report feelings of discomfort when visiting friends and relatives in their homeland. They feel they are not well understood. Arguably social norms from non-cosmopolitan individuals and groups could inhibit the display of cosmopolitan consumption practices by members of the community. The community offers them a chance to have their experiences, preferences and tastes validated by other community members and to embrace cosmopolitan values linked to notions of flexibility and adaptability. The community therefore speeds up the process of becoming cosmopolitans. 
The cosmopolitan community acts a community of practice. The cosmopolitan identity is constituted by and performed through many different practices (ways of doing things) - see (Schau, Muñiz Jr, and Arnould, 2009). Communities of practice are formed by people who engage in a process of collective learning in a shared domain (Wenger, McDermott, and Snyder, 2002). Members of Intercultures share practical knowledge on many issues that are important to the development of a cosmopolitan identity and which is normally linked to "how to" processes. These cosmopolitan practices involve ways of dealing with local culture, ways of coping with distant relationships, ways of behaving in public and privately and all kinds of cultural translations. Cosmopolitan practices also encompass a number of consumption practices which include consuming objects, services, brands and places. In these communities, members learn important cosmopolitan skills such as knowing where to go for bargain and upscale shopping, how to find good schools for their children, how to rent furniture when moving in, how to find storage places and spread possessions through friends and family houses when moving out, how to get a job in a new country. Because these skills can be learned, cosmopolitan groups can be especially attractive to members as a means of honing these skills. The literature on communities of practice (Wenger, McDermott, and Snyder, 2002) shows that firms can explore their potential developing, validating and disseminating specific consumption practices that are beneficial to the firm.

\section{Conclusion}

This study extends current research on cosmopolitanism in marketing by exploring the role of communities in shaping cosmopolitan identity. Current views on cosmopolitanism have underplayed the role of communities in shaping cosmopolitan identities. The current study shows that a cosmopolitan community can shape consumers' cosmopolitan identity in many ways: a) by promoting a different polarity (cosmopolitan-parochial instead of cosmopolitanlocal) it shifts how consumption practices are used to maintain symbolic boundaries, b) by validating cosmopolitan ideals and preferences, it works as a catalyst in the process of becoming a cosmopolitan consumer, c) by functioning as a community of practice, it provides cosmopolitan knowledge and skills which directly influence consumer choice and usage of products, services, places and brands.

Among its practical implications, it suggests that marketers should pay more attention to cosmopolitan communities as they provide a quick access to understanding the symbolic boundaries and socio-cultural forces responsible for the dynamic and contextual nature of cosmopolitan identity. Marketing strategy based on this knowledge might be more effective than based on a notion of a de-contextualized cosmopolitan orientation. Moreover, marketers could take advantage of communities as part of their market strategies, as they could help instill product use within the learning processes of cosmopolitan knowledge and skills and disseminate desired cosmopolitan consumption practices. 


\section{References}

Bearden, W., Etzel, M., 1982. Reference group influence on product and brand purchase decisions. Journal of Consumer Research 9 (September), 183-194.

Burawoy, M., 1998. The Extended Case Method. Sociological Theory 16 (1), 4-33.

Caldwell, M., Blackwell, K., Tulloch, K., 2006. Cosmopolitanism as a consumer orientation.

Qualitative Market Research 9 (2), 126-139.

Cannon, H., Yoon SJ, McGowan L, Yaprak, A., 1994. In search of the global consumer Proceedings of Annual meeting of the Academy of International Business 1994.

Cannon, H. M., Yaprak, A., 2002. Will the real-world citizen please stand up! The many faces of cosmopolitan consumer behavior. Journal of International Marketing 10 (4), 30-52.

Cleveland, M., Laroche, M., Papadopoulos, N., 2009. Cosmopolitanism, Consumer Ethnocentrism, and Materialism: An Eight-Country Study of Antecedents and Outcomes. Journal of International Marketing 17 (1), 116-146.

Cova, B., 1997. Community and consumption: Towards a definition of the linking value of product or services. European Journal of Marketing 31 (3/4), 297-316.

Goffman, E., 1959. The presentation of self in everyday life. Doubleday Anchor, Garden city, NY.

Holt, D. B., 1997. Poststructuralist Lifestyle Analysis: Conceptualizing the Social Patterning of Consumption in Postmodernity. Journal of Consumer Research 23 (4), 326-350.

Holt, Douglas B., 1998. Does Cultural Capital Structure American Consumption? Journal of Consumer Research 25 (1), 1-25.

Kozinets, R., 2010. Netnography: Doing Ethnographic Research Online. Sage, Thousand Oaks, CA.

Kozinets, R. V., 2002. The field behind the screen: using netnography for marketing research in online communities. Journal of Marketing Research 1 (Feb), 61-72.

Marcus, G. E., 1995. Ethnography in/of the world system: the emergence of multi-sited ethnography. Annual review of anthropology 24 (1), 95-117.

Moschis, G. P., 1976. Social comparison and informal group influence. Journal of Marketing Research 13 (August), 237-244.

Riefler, P., Diamantopoulos, A., 2009. Consumer cosmopolitanism: Review and replication of the CYMYC scale. Journal of Business Research 62 (4), 407-419.

Schau, H. J., Muñiz Jr, A. M., Arnould, E. J., 2009. How Brand Community Practices Create Value. Journal of Marketing 73 (5), 30-51.

Schouten, J. W., McAlexander, J. H., 1995. Subcultures of Consumption: An Ethnography of the New Bikers. Journal of Consumer Research 22 (1), 43. 
Skeggs, B., Binnie, J., 2004. On Cosmopolitan Sexualities: Disrupting the Logic of Late Capitalism Sociological Review 52 (1), 39-62.

Thompson, C. J., Tambyah, S. K., 1999. Trying to be cosmopolitan. Journal of Consumer Research 26 (3), 214-241.

Wenger, E., McDermott, R. A., Snyder, W., 2002. Cultivating communities of practice: A guide to managing knowledge. Harvard Business Press, Boston, MA.

Yoon, S., 1998. Dimensionality of the cosmopolitanism construct: cross-method validation of the Emic and Etic interpretations. Proceedings of Asia Pac Adv Consum Res, 81-88. 